\title{
Reduced Fc\&RI-Mediated Release of Asthma-Promoting Cytokines and Chemokines from Human Basophils during Omalizumab Therapy
}

\author{
Janet M. Oliver ${ }^{a}$ Christy A. Tarleton ${ }^{a}$ Laura Gilmartin ${ }^{a}$ Tereassa Archibeque ${ }^{b}$ \\ Clifford R. Qualls $^{\mathrm{b}} \quad$ Lorena Diehl $^{\mathrm{b}}$ Bridget S. Wilson ${ }^{\mathrm{a}}$ Mark Schuyler $^{\mathrm{b}}$ \\ Departments of a Pathology and ${ }^{\mathrm{b}}$ Medicine, University of New Mexico School of Medicine, Albuquerque, \\ N. Mex., USA
}

\section{Key Words}

Basophils $\cdot$ Cytokine $\cdot$ Chemokine $\cdot$ Histamine $\cdot$ Asthma .

Omalizumab $\cdot$ Xolair $^{\circledR} \cdot \lg$ E receptor $\cdot$ Fc R RI

\begin{abstract}
Background: Treating asthmatics with the humanized IgEscavenging antibody, omalizumab (rhuMAb-E25, Xolair $^{\circledR}$ ), reduces airways inflammation and asthma symptoms. Previously, omalizumab was shown to cause a dramatic and reversible loss of cell surface high-affinity lgE receptors, Fc $\varepsilon$ RI, from the peripheral blood basophils of asthmatics. The consequences of receptor loss for the Fc\&RI-mediated synthesis and release of cytokines implicated in allergic asthma have not been examined. Methods: Fifteen asthmatic volunteers each received omalizumab for 12 weeks. Peripheral blood basophils were isolated before, during, 2 weeks after and 6 months after omalizumab. Basophils were assayed for the basal and anti-IgE-stimulated release of cytokines, chemokines and histamine. Pooled data were analyzed by repeated measures ANOVA and by paired t tests. Results: Anti-lgEstimulated human basophils synthesize and release Th2 cytokines (IL-4, IL-13) and chemokines (IL-8, RANTES). The antiIgE-stimulated release of IL-4, IL-13 and IL-8 was reduced during omalizumab treatment and returned to pretreatment levels after omalizumab withdrawal. Omalizumab did
\end{abstract}

not alter basophil histamine levels or basal and anti-lgEstimulated histamine release. Conclusions: Omalizumab may reduce asthma symptoms in part by suppressing the FceRI-mediated production by basophils of Th2 cytokines and selected chemokines. Anti-lgE-stimulated basophil cytokine synthesis appears more sensitive than histamine release to the loss of Fc\&RI caused by omalizumab treatment.

Copyright $\odot 2009$ S. Karger AG, Basel

\section{Introduction}

Omalizumab (rhuMAb-E25, Xolair $^{\circledR}$ ) is a humanized recombinant monoclonal antibody that binds the Fc portion of circulating IgE, preventing its binding to receptors on basophils and mast cells and clearing free IgE from the blood [1-3]. In clinical trials, omalizumab reduced both the early- and late-phase responses to inhaled allergen [4-6]. Omalizumab typically improves asthma control and quality of life and allows a significant reduction in corticosteroid use among patients with asthma $[2,7]$. In particular, omalizumab treatment strongly reduces asthma exacerbations, defined as adverse events requiring hospitalization $[8,9]$.

The mechanism of omalizumab action is incompletely understood. Unlike steroids, omalizumab does not

\section{KARGER}

() 2009 S. Karger AG, Basel

Fax +4161306 1234

E-Mail karger@karger.ch

www.karger.com www.karger.com/iaa
Correspondence to: Dr. Janet M. Oliver

Department of Pathology, Cancer Research Facility, Room 201

University of New Mexico Health Sciences Center

Albuquerque, NM 87131 (USA)

Tel. +1 505272 4364, Fax +1 505272 1435, E-Mail joliver@salud.unm.edu 
improve nonspecific bronchial hyperresponsiveness and does not have large effects on lung function [10]. It does, however, reduce bronchial mucosal inflammation, as demonstrated by decreases in airways and induced sputum eosinophil numbers as well as by reductions in IgEpositive cells, in T and B lymphocytes and in IL-4-containing cells in bronchial biopsies $[9,10]$.

The most dramatic effect of omalizumab is its ability to reduce levels of the high-affinity IgE receptor, FceRI, on peripheral blood basophils by approximately $90 \%$ in a week and by $99 \%$ with longer treatment [11-13]. This reduction in receptor levels occurs because IgE binding is required to stabilize $\mathrm{F} c \varepsilon \mathrm{RI}$ at the basophil membrane [14]. Signaling though the FceRI causes the synthesis and release of substantial amounts of the Th2 cytokines IL-4 and IL-13 that are critical for initiating and maintaining allergic responses [15-22]. FceRI signaling also stimulated the production of chemokines, particularly IL-8, that stimulate inflammatory cell chemotaxis [22]. We therefore speculated that reducing FceRI levels with omalizumab may reduce airways inflammation in part by reducing the FceRI-mediated production by basophils of asthma-promoting cytokines and chemokines. The hypothesis was consistent with results from several recent studies on mouse models of chronic inflammation. In one case, allergen-induced eosinophilic infiltration leading to delayed-onset ear swelling was abolished in FceRI-deficient mice and restored, independently of mast cells and $\mathrm{T}$ cells, by the transfer of basophil-enriched fractions of bone marrow cells from normal mice [23]. In another report, allergen-induced ear swelling due to massive infiltration of eosinophils and other cells was abolished by treating normal mice with a basophil-depleting antibody [24]. Because basophils accounted for only 1$2 \%$ of the infiltrating cells in allergen-treated normal mice, the authors proposed that chemokines and cytokines generated by FceRI signaling in antigen-stimulated basophils were responsible, directly or indirectly, for the recruitment of the other inflammatory cells.

In this study, we measured basal and anti-IgE-stimulated histamine, cytokine and chemokine production by basophils from volunteers with a diagnosis of intermittent asthma over 12 weeks of omalizumab treatment and 6 months of withdrawal. Our data reveal a significant reduction in the synthesis of asthma-promoting chemokines and cytokines. We discuss the possibility that this basophil response could contribute to the reduced airways inflammation observed in response to omalizumab in humans with asthma.

\section{Subjects and Methods}

Percoll was from Pharmacia (Uppsala, Sweden) and Midimacs magnetic columns were from Miltenyi Biotec (Auburn, Calif., USA). The $\mathrm{Ca}^{2+}$ ionophore, A23187, was from Sigma (St. Louis, Mo., USA). Affinity-purified goat anti-human IgE (anti-IgE) and IL-4 ultrasensitive ELISA kits were from Biosource (Camarillo, Calif., USA). ELISA kits for IL-13, IL-8, RANTES and leptin were from RayBio (Norcross, Ga., USA). Human histamine ELISA kits were from Beckman Coulter (Fullerton, Calif., USA). Luminex assays were performed using the Biosource Human Thirty-Plex Antibody Bead Kit that tests for over 30 cytokines, chemokines and growth factors, with the addition of IL-3 and Leptin Antibody Bead Kits. The anti-human FceRI $\alpha$-subunit monoclonal antibody, 22E7, was a generous gift from Dr. J. Kochan, Roche Pharmaceutics and Dr. A. Gilfillan, NIH. Omalizumab for subcutaneous use was provided by Genentech, through the courtesy of Dr. Robert Fick.

Human Subjects

This study was approved by the Human Research Review Committee at the University of New Mexico Health Science Center. Allergy skin testing, spirometry and methacholine challenges and phlebotomy were performed in the UNM General Clinical Research Center as previously described [21,22]. The study began with the recruitment of subjects with self-reported asthma who were atopic based on positive skin reactions to at least 2 common local allergens. Intermittent asthmatics were selected from this cohort based on their spirometry symptoms and medication use (http://www.nhlbi.nih.gov/guidelines/asthma/asthgdln.htm). None of the subjects currently smoked (confirmed by serum cotinine measurements) and none was obese. Their only medication was occasional albuterol. None had been using inhaled steroids or had received allergen immunotherapy for at least 5 years before onset of the study. Mean age was 19 years (range 18-45).

Four males and 11 females entered the study. Their mean serum IgE levels, measured at Tricore Reference Laboratories (Albuquerque, N. Mex., USA), were $207 \pm 32 \mathrm{IU} / \mathrm{ml}$. Subjects received omalizumab subcutaneously every 4 weeks for a total of 12 weeks. The standard dose, based on weight and initial levels of circulating IgE, was $0.016 \mathrm{mg}$ omalizumab/kg/IU/ml (http:// www.xolair.com/hcp/dosing.jsp). Blood was drawn for analysis of basophil function on 5 separate occasions: 2-14 days before the first omalizumab injection (visit $1 ; \mathrm{V} 1$ ), at 2 weeks (V2) and 8 weeks (V3) after beginning omalizumab treatment, within 2 weeks of the last omalizumab injection (V4) and at 6 months (V5) after the last omalizumab injection. The treatment and phlebotomy schedules are shown in figure 1a.

\section{Basophil Purification and Activation}

Basophils were purified from $115 \mathrm{ml}$ peripheral venous blood as described [21, 22]. Briefly, Percoll gradient centrifugation was used to generate $1-47.5 \%$ pure basophils, followed by negative selection to $82.5-99 \%$ basophils. The average yield of purified basophils was 2.8 million cells (range $0.8-4.8$ million).

Some Percoll-enriched basophil preparations were assayed for FceRI expression levels using FITC-conjugated 22E7, an antiFceRI $m A b$ that labels both IgE-bound and unoccupied receptors. Simply Cellular beads (Bangs Laboratories, Fishers, Ind., USA) were used as standards. 
Basophils from all 15 subjects were assayed immediately after Percoll enrichment for histamine release as in Youssef et al. [21]. Briefly, cells in 1 (of 16) tubes from the Percoll gradient were washed and resuspended in Hanks' buffered salt solution, then divided into 8 portions. Two aliquots of basophils were lysed using 3 freeze-thaw cycles, centrifuged and supernatants stored frozen for assays of total histamine content. The remaining aliquots were incubated in duplicate for $30 \mathrm{~min}$ at $37^{\circ} \mathrm{C}$ with or without $1.0 \mu \mathrm{g} / \mathrm{ml}$ anti-IgE or $1 \mu \mathrm{g} / \mathrm{ml} \mathrm{A23187.} \mathrm{Supernatants} \mathrm{recovered} \mathrm{by}$ centrifugation were stored frozen for ELISA assays. Degranulation was expressed as histamine released to the medium as percent of total histamine. A23187 served as an internal control for the degranulation assay.

The negatively selected basophils from 9 of the subjects were assayed immediately after purification for cytokine production. Cells were washed and resuspended in Hanks' buffered salt solution, then divided into 6 or more portions. Two portions of cells were lysed using 3 freeze-thaw cycles for assays of preformed cytokines. Four portions of cells were incubated in duplicate for $4 \mathrm{~h}$ at $37^{\circ} \mathrm{C}$ with or without $1.0 \mu \mathrm{g} / \mathrm{ml}$ anti-IgE as described previously [22]. Supernatants and lysates were stored frozen until analysis.

Anti-IgE concentrations and length of incubation for degranulation and cytokine assays were selected based on the results of earlier studies $[19,21,22]$, with confirmation by further preliminary experiments. No priming agent was added to our buffers. Previous groups have reported that IL-13 is produced more slowly than IL-4 by basophils [18]. However, in our hands, production of both cytokines in response to $1.0 \mu \mathrm{g} / \mathrm{ml}$ anti- $\operatorname{IgE}$ is near-maximal in $4 \mathrm{~h} \mathrm{[22].} \mathrm{Previous} \mathrm{groups} \mathrm{[11,} \mathrm{12]} \mathrm{have} \mathrm{also} \mathrm{found} \mathrm{lower}$ percent-stimulated histamine release than is reported here and in our previous papers $[19,21,22]$. The difference may reflect our more rapid and gentle isolation procedure.

Enzyme-Linked Immunosorbent Assays

Basophil supernatants were assayed in duplicate by ELISA for histamine, IL-4, IL-8, IL-13, RANTES and leptin according to the manufacturers' instructions. Assay sensitivities were: IL-4, 0.39 pg/ml; IL-13, 8.23 pg/ml; IL-8/CXCL8, 0.27 pg/ml; RANTES, 2.74 $\mathrm{pg} / \mathrm{ml}$; leptin, $4.1 \mathrm{pg} / \mathrm{ml}$; histamine, $0.05 \mathrm{nM}$. Cytokine production was expressed as picogram per $10^{6}$ cells. Histamine release data were expressed as percent of total histamine content.

\section{Luminex Assays}

The same basophil supernatants were analyzed in duplicate for cytokines and chemokines using the Luminex bead-based assay. Assay sensitivities were: IL-4, $5.6 \mathrm{pg} / \mathrm{ml}$; IL-8, $7.2 \mathrm{pg} / \mathrm{ml}$; RANTES, 10.4 pg/ml; leptin, $18.6 \mathrm{pg} / \mathrm{ml}$. Data were collected using a Luminex LX100 system (Luminex Corporation, Austin, Tex., USA). Initial data analysis used Brendan Scientific's StatLia 3.2 , curve fitting and statistical analysis package.

\section{Statistical Analyses}

Data from all volunteers were pooled and analyzed to generate a mean cytokine or histamine value \pm SEM for the 5 different time points and for 2 treatment conditions, resting and crosslinked using anti-IgE. Repeated measures ANOVA analysis with treatment and time as repeated factors was used to determine if basal and anti-IgE-stimulated cytokine or histamine production were different from each other and also if IgE-stimulated cyto-
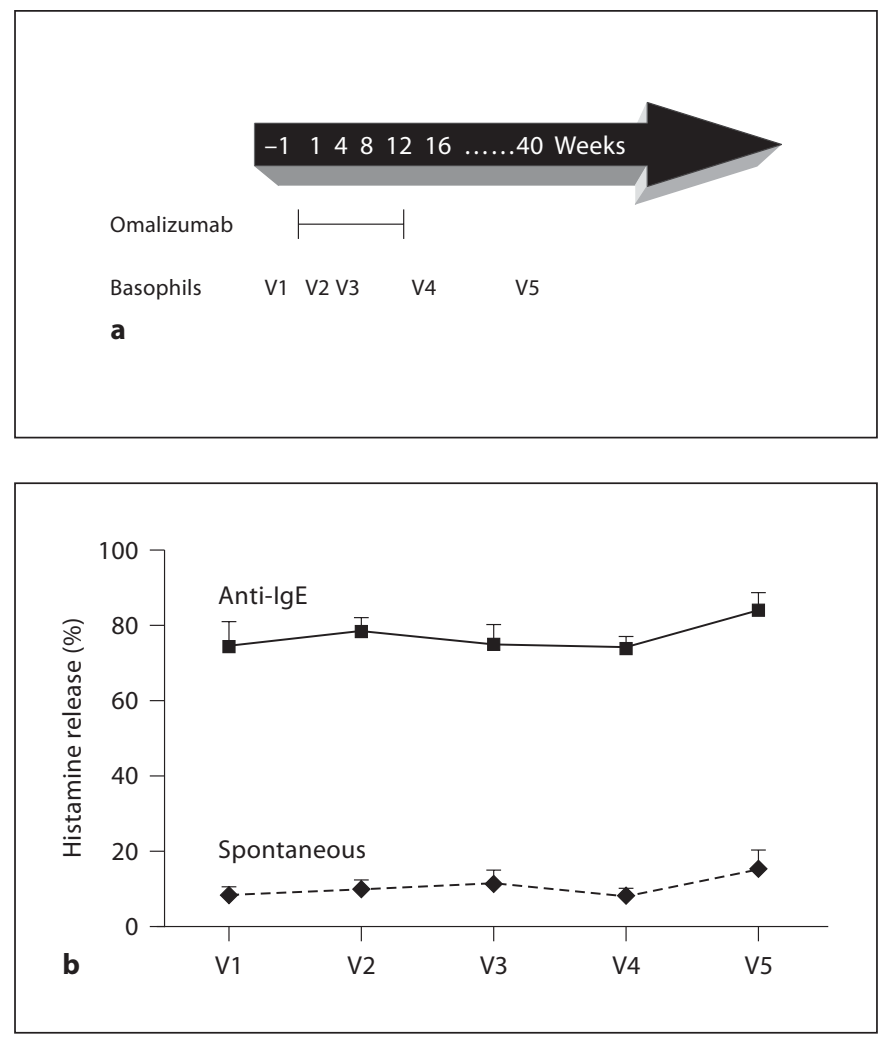

Fig. 1. Omalizumab does not reduce anti-IgE-stimulated histamine release. Percoll-enriched basophils from 15 volunteers were analyzed for basal and anti-IgE-stimulated histamine release over a 12-week course of omalizumab treatment and withdrawal. a The arrow shows when drug was first and last injected and when blood was taken for basophil purification and degranulation assays. Basophils were isolated before treatment (V1), at 2 weeks (V2) and 8 weeks (V3) after beginning treatment, within 2 weeks after the last treatment (V4) and 6 months after the last treatment (V5). b The graph shows histamine release \pm SEM in the presence and absence of $1 \mu \mathrm{g} / \mathrm{ml}$ anti-IgE measured over $30 \mathrm{~min}$ as percent of total histamine content of the cells. Repeated measures ANOVA comparing between treatment groups found that anti-IgEstimulated release is significantly higher than basal release under all treatment conditions $(\mathrm{p}<0.001)$. There was no significant effect of omalizumab on anti-IgE-stimulated histamine release across the time course of omalizumab treatment and withdrawal.

kine or histamine production varied across the time course of omalizumab treatment and withdrawal. When repeated measures ANOVA showed differences across the time course of treatment and recovery, paired $t$ tests were used to identify where the samples differed. All statistical analyses used the Statistical Analysis Software package version 9.1 (SAS, Cary, N.C., USA). When variables showed positively skewed distributions of values, values were log transformed prior to data analysis (for more normally distributed outcomes). A p value of $<0.05$ was considered statistically significant. 


\section{Results}

\section{Omalizumab Depletes Basophil FceRI $\alpha$}

In initial studies, we confirmed previous evidence [1113] for at least a 96\% decrease in Fc\&RI $\alpha$ levels between V1 (immediately before the first injection of omalizu$\mathrm{mab}$ ) and V4 (2 weeks after the last omalizumab injection) in 2 of our subjects (from 70,029 to 1,373 receptors per cell in subject 184 ; from 84,421 to 3,150 receptors/cell in subject 010 ). Having replicated well-documented prior work, we focused all future basophil preparations on assays for histamine, cytokine and chemokine production before, during and after exposure to omalizumab.

\section{Omalizumab Does Not Affect Basal or}

\section{Anti-IgE-Stimulated Histamine Release}

We reported previously [21] that basophils from asthmatic volunteers release a higher percentage of their total stored histamine than control basophils in response to anti-IgE challenge. Thus, it was of interest to determine if the strong anti-IgE-induced histamine release response of basophils from asthmatics is attenuated during exposure to omalizumab. Analysis of degranulation data by repeated measures ANOVA found no significant differences in either basal or anti-IgE-mediated percent histamine release over the 12 weeks of omalizumab treatment and 6 months of recovery (fig. 1). As expected, there was also no effect of omalizumab on degranulation induced by A23197, a calcium ionophore that bypasses the IgE receptor and its associated tyrosine kinases and tests for the integrity of downstream events leading to secretion (not shown).

Because we measured both the total histamine content and the percent of basophils in every cell preparation, it was possible to determine if omalizumab alters either basophil numbers or basophil histamine content. Under the assumption that basophils are the only source of histamine in Percoll-enriched fractions, further repeated measures ANOVA found no significant differences across the time course of treatment and recovery either in histamine per $10^{6}$ total leukocytes $(\mathrm{p}=0.38)$ or in histamine per $10^{6}$ basophils $(\mathrm{p}=0.78)$.

\section{Omalizumab Reduces Anti-IgE-Mediated IL-4, IL-8} and IL-13 Production

Increased production of the Th2 cytokines, IL- 4 and IL-13, and of the chemokine, IL-8, occurs as a robust response to FceRI cross-linking in human basophils [1522]. We therefore selected these 3 molecules for initial analyses of basophil cytokine and chemokine responses to 12 weeks of omalizumab treatment followed by 6 months of withdrawal. Cytokine assays were performed using basophils from the last 9 (of 15) volunteers. Since there was no difference in selection criteria in course of the project, we felt confident that any differences between the histamine release and cytokine production data could not be based on selection bias.

Results from ELISA (fig. 2) showed that basal production of IL-4, IL-13 and IL-8 during a 4-hour incubation is very low and is not affected by omalizumab. Anti-IgE treatment stimulates the production of all 3 mediators by basophils from intermittent asthmatics. Importantly, omalizumab treatment significantly reduces anti-IgEstimulated production of basophil IL-4, IL-13 and IL-8, while its withdrawal permits a strong recovery. Differences, indicated by asterisks, are strongest at V3 and V4, at 8 and 14 weeks after beginning treatment, respectively. IL-13 production was also significantly reduced after only 2 weeks of treatment.

\section{Effects of Omalizumab on the Production of Other Mediators}

We repeated the measurements when Luminex multiplex array technology became available, in order to scan a wider range of cytokines. Results from Luminex assays on stored frozen supernatants from 9 subjects strongly confirmed the responses to anti-IgE stimulation and to omalizumab treatment already observed for IL-8 and IL-4 (Pearson's correlation $\mathrm{p}<0.0001$ for comparison of trends between the Luminex and ELISA data for these 2 cytokines; illustrated for IL- 8 in fig. $3 \mathrm{a}$ ). Absolute IL-4 and IL-8 levels were less well replicated between the assays, perhaps because the ELISA and Luminex kits used different antibodies. IL-13 was not detected in the Luminex panel. We previously validated IL-13 expression in anti-IgE-stimulated basophils by PCR and by Cartesian array analysis [22]. Furthermore, robust anti-IgE-stimulated basophil IL-13 production was measured in many previous ELISA $[16-18,20]$ and RT-PCR [22] analyses. Previous authors have also reported poor correlation between ELISA and Luminex assays for IL-13 [25]. We therefore have confidence in the ELISA results.

We discovered by ANOVA analysis of Luminex data that the chemokine, RANTES, is produced at low levels by resting basophils and at higher levels by anti-IgE-activated basophils (fig. 3b), and we confirmed this result by ELISA (analysis based on supernatants from 6 of the 9 subjects; data not shown). No significant differences in anti-IgE-stimulated RANTES production were observed 


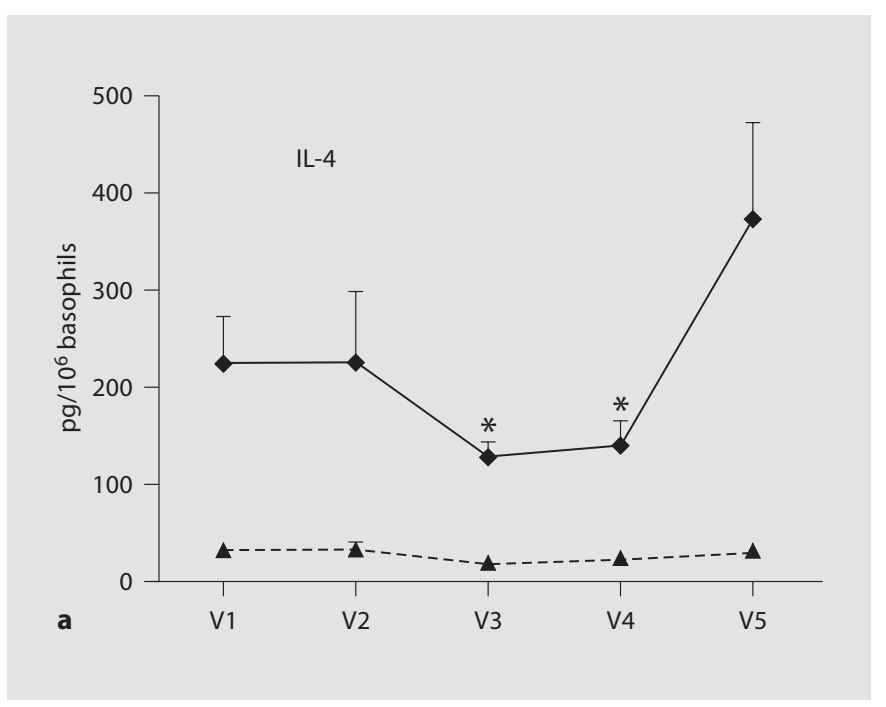

Fig. 2. Omalizumab inhibits anti-IgE-mediated IL-4, IL-13 and IL-8 production. Basophils were isolated by Percoll gradient centrifugation followed by negative selection from 9 volunteers before, during and 6 months after a 12-week course of omalizumab. Cells were incubated for $4 \mathrm{~h}$ without (dashed lines) or with (solid lines) $1 \mu \mathrm{g} / \mathrm{ml}$ anti-IgE. Supernatants were analyzed by ELISA for IL-4 (a), IL-13 (b) and IL-8 (c) production. Repeated measures ANOVA comparing between treatment groups confirmed that anti-IgE stimulation causes a substantial increase in the synthesis and release of all 3 mediators ( $\mathrm{p}<0.001$ for IL- 4 ; $\mathrm{p}=0.006$ for IL$13 ; \mathrm{p}=0.009$ for IL-8). Further ANOVA comparing across the time course of treatment confirmed that omalizumab significantly alters anti-IgE-stimulated mediator production $(\mathrm{p}=0.03$ for IL-4; $\mathrm{p}<0.001$ for IL-13; $\mathrm{p}<0.001$ for IL-8). Asterisks mark the specific time points when omalizumab significantly reduced anti-IgE-stimulated mediator production (results of paired t tests yielding $\mathrm{p}<0.05$ in comparison with pre- and posttreatment $\mathrm{cy}$ tokine production).

across the time course of omalizumab treatment and withdrawal.

Previous Cartesian array analysis and ELISA had shown that human basophils produce the adipokine, leptin [22]. The Luminex assay confirmed the earlier observations. ANOVA found no significant effect of either anti-IgE stimulation or omalizumab treatment on the production of leptin by basophils (fig. 3c). The same result was obtained by ELISA (analysis based on supernatants from 6 of the 9 subjects; data not shown).

Other mediators that appeared to be strongly present by Luminex analysis included hepatocyte growth factor, IL-7 and IL-17 [for reservations about IL-17, see 22]. MCP1, MIP1 $\alpha$ and MIP1 $\beta$ were also present in most sam-
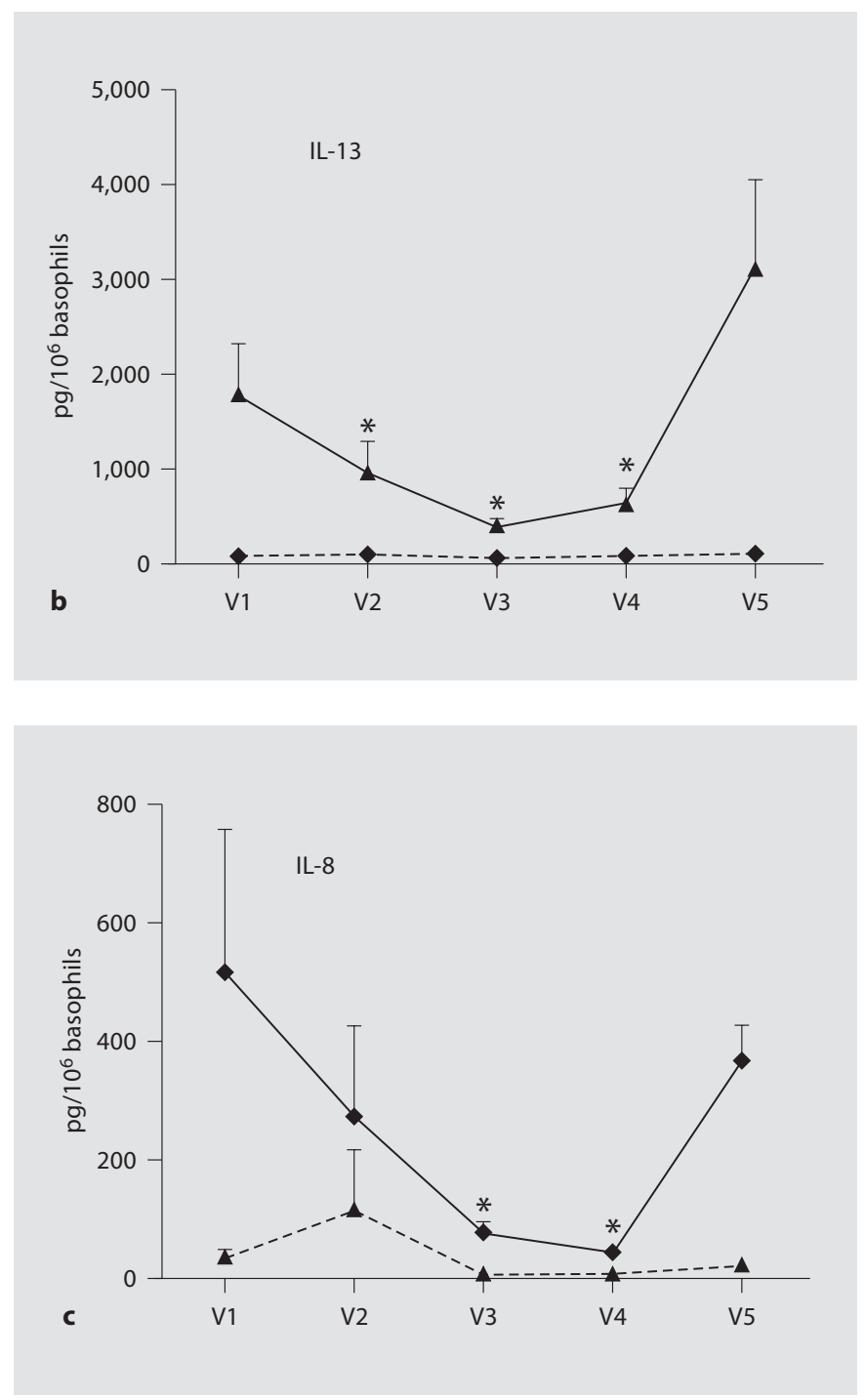

ples. None of these mediators responded significantly to either anti-IgE stimulation or omalizumab treatment. No independent assays were performed to confirm these observations.

\section{Basophils Synthesize Cytokines and Chemokines \\ de novo}

Lysates from freshly purified basophils were included in both the ELISA and Luminex assays. Levels of preformed mediators were below the limits of detection (data not shown). Thus, the cytokines and chemokines detected in supernatants from anti-IgE-stimulated basophils are largely synthesized during the activation period. 


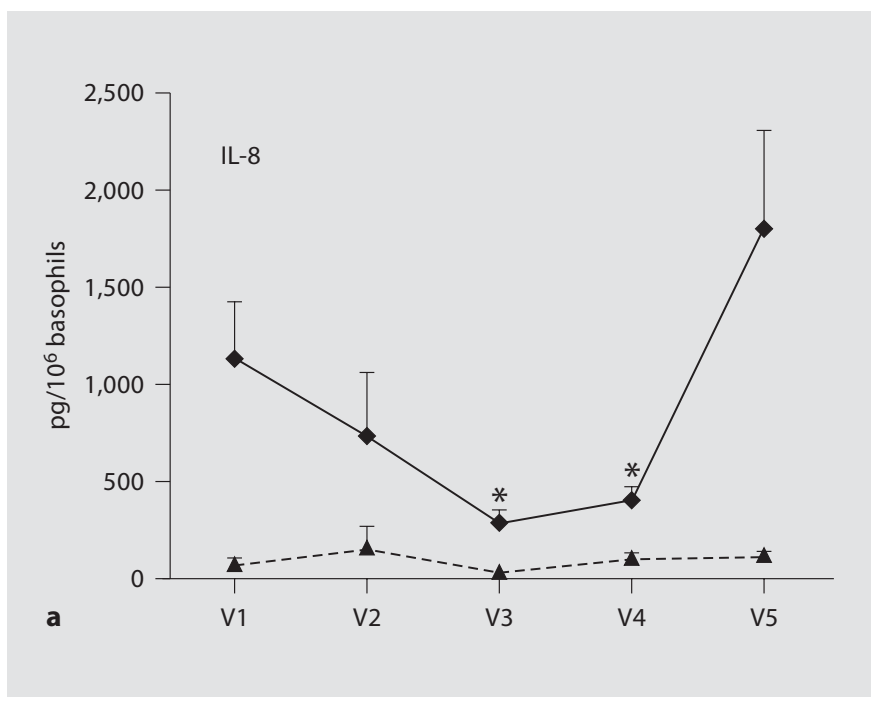

Fig. 3. Effects of anti-IgE and omalizumab on IL-8, RANTES and leptin production. Supernatants from resting and activated (with $1 \mu \mathrm{g} / \mathrm{ml}$ anti-IgE) basophils from 9 volunteers were re-analyzed for a panel of cytokines by Luminex assays. a Luminex data for IL-8 replicate the ELISA evidence (fig. 2) for increased cytokine production in response to anti-IgE ( $\mathrm{p}=0.009$ for differences between resting and anti-IgE-stimulated cells) and for reduced antiIgE-stimulated cytokine production during omalizumab treatment $(p=0.01$ for differences across the time course of omalizumab treatment and withdrawal). Asterisks localize the differences identified by paired t-tests ( $\mathrm{p}<0.05$ in comparison with pre- and post-treatment cytokine production). b Luminex data for RANTES also showed increased cytokine production in response to anti-IgE ( $\mathrm{p}=0.01$ for the comparison between resting and anti-IgE-stimulated cells). However, differences in anti-IgEstimulated RANTES production across the time course of omalizumab treatment and withdrawal were not significant by ANOVA. c Leptin production was not affected significantly by either anti-IgE stimulation or omalizumab.

\section{Discussion}

Allergic asthma is a chronic lung disease characterized by airflow obstruction, bronchial hyperreactivity and inflammation of the airways. The clinical benefits of therapy with the IgE-scavenging antibody, omalizumab (rHuMab E25, Xolair), in patients with allergic asthma and allergic rhinitis emphasize the fundamental importance in allergic inflammation of IgE and its high-affinity receptor, FceRI, expressed primarily on basophils and mast cells [3].

One consequence of omalizumab treatment is a rapid, extensive (>95\%) and reversible reduction of FceRI expression on circulating basophils [11-13]. It has not been
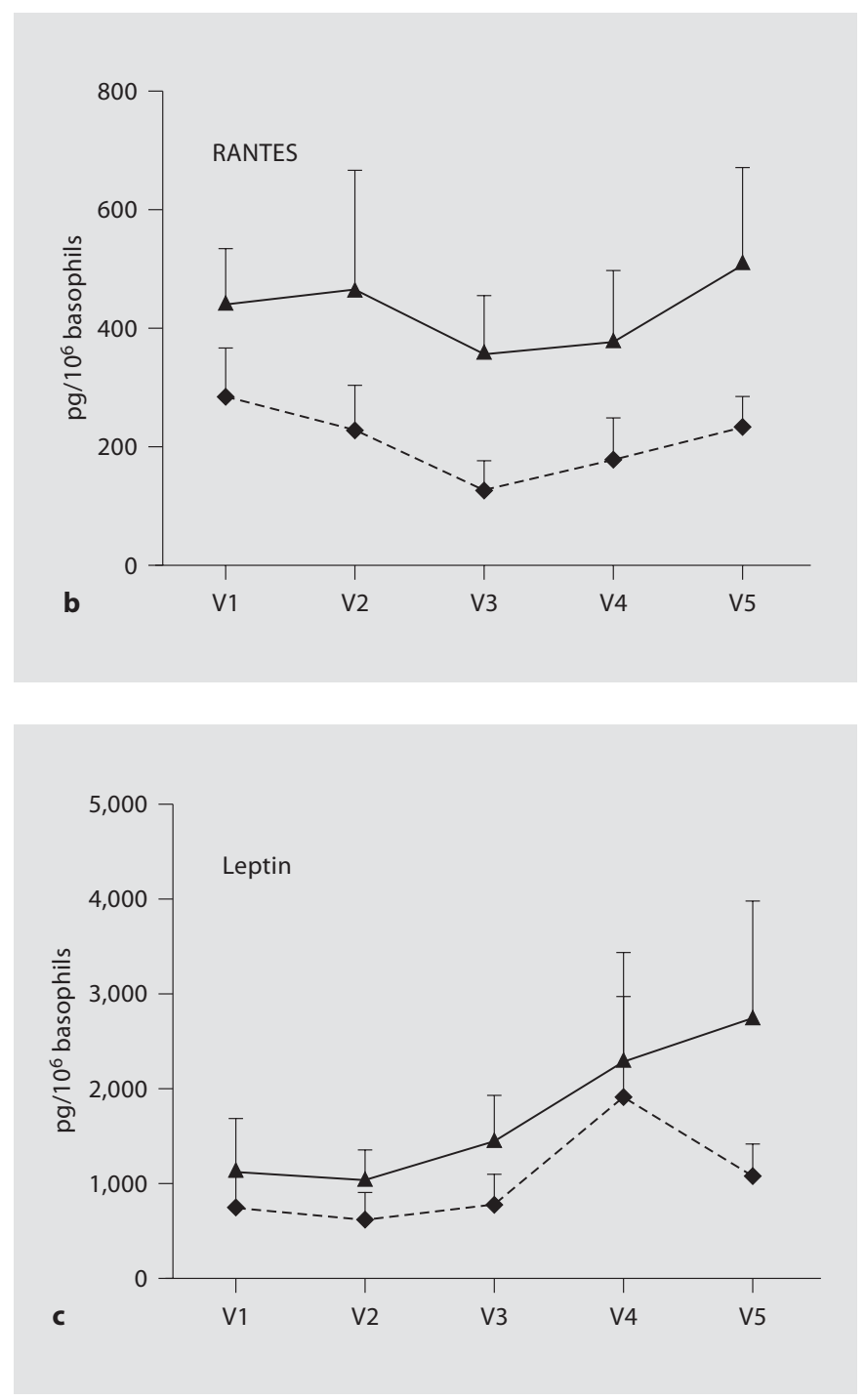

clear if the loss of basophil receptors is important per se for the improved health of patients receiving omalizumab or if loss of basophil receptors is simply a surrogate for similar changes occurring in other less accessible FceR1-expressing cells, particularly mast cells and dendritic cells often considered more immediate contributors to the initiation and progression of asthma [26, 27]. There are no reports as yet on changes in FceRI expression on lung mast and dendritic cells in response to omalizumab. However, Prussin et al. [28] described an omalizumab-induced reduction in FceRI expression on circulating dendritic cells from 16 subjects that followed a similar time course to basophils but was less extensive (maximally 52 and $83 \%$ loss for the pDC1 and pDC2 sub- 
sets, respectively). Beck et al. [13] reported a loss of receptors on skin mast cells in 3 subjects, and showed that the loss occurred 10 times more slowly than the loss in circulating basophils. These relatively modest changes encouraged the hypothesis that the highly omalizumab-responsive basophil may be directly involved in human asthma.

We began our analyses by determining if omalizumab affects histamine release from basophils. Basophil antiIgE-stimulated percent histamine release was measured in duplicate in 15 volunteers on 5 separate occasions before, during and after a 12-week course of treatment following the current subcutaneous route of administration. Results of statistical analyses over multiple donors and times showed clearly that treatment with omalizumab using current dosing protocols does not affect antiIgE-stimulated percent histamine release.

There is no conflict between the current data and previous evidence that percent degranulation in response to dust mite allergen is $90 \%$ reduced after 12 weeks of intravenous omalizumab $[11,12]$. By stimulating with a relatively high concentration of anti-IgE, our experiments are expected to engage essentially all remaining IgE-receptor complexes. In contrast, levels of dust mite-specific IgE bound to FceRI are likely infinitesimal when total $\operatorname{IgE}-\mathrm{F} c \varepsilon \mathrm{RI}$ is already very low.

In contrast to our data, the earlier investigators also reported an approximately $40 \%$ reduction in percent anti-IgE-stimulated histamine release after 12 weeks of omalizumab $[11,12]$. The use of higher omalizumab doses in the earlier studies provides a possible explanation for this discrepancy. In the first study [11], volunteers received biweekly intravenous omalizumab at 2 doses, one double the dose used here, and the text describes 'significant variability among donor basophil responses with nearly no change in the response to anti-IgE $\mathrm{Ab}$ in some donors'. In the subsequent study [12], percent anti-IgEstimulated degranulation was measured in basophils from 15 volunteers at the end of 12 weeks of substantially more vigorous therapy than is currently used, including 3 intravenous omalizumab doses in week 1 of treatment followed by biweekly maintenance infusions. When maintenance doses were reduced towards current levels and frequencies, and degranulation redetermined 34 weeks later, anti-IgE-stimulated degranulation rebounded towards (allergen-stimulated) and above (anti-IgEstimulated) pretreatment levels. These results are consistent with our conclusion that current omalizumab dosage schedules do not reduce anti-IgE-mediated percent histamine release.

Omalizumab Reduces Basophil Cytokine Production
Because histamine has been implicated in the longterm regulation of inflammatory responses [29], it was of interest to determine if omalizumab affects the circulating numbers or histamine content of basophils even if it does not affect percent anti-IgE-stimulated histamine release. Statistical analysis found no effect of omalizumab treatment and withdrawal on total histamine levels in Percoll-enriched fractions whether expressed as histamine per $10^{6}$ total leukocytes or when corrected to histamine per $10^{6}$ basophils. These results suggest that a short course of omalizumab does not alter either basophil numbers or basophil histamine content. Previously, Saini et al. [12] measured the histamine content of lysed whole blood and also found no differences resulting from omalizumab treatment.

The inflammatory environment that predisposes to asthma is maintained by Th 2 cytokines. Therefore, we expanded our studies to determine the effects of omalizumab on basophil cytokine and chemokine production. Mast cells and Th2 lymphocytes are traditionally considered to be the main sources of asthma-promoting cytokines, especially IL-4 and IL-13, in human asthma [26, 27, 30]. However, it is clear that basophils also produce Th2 cytokines [15-22] and there is a long history of research implicating basophil-derived mediators in human allergic inflammation and asthma [26, 31-34].

We demonstrated by ELISA that basal production of IL-4, IL-8 and IL-13 is very low in basophils from volunteers with intermittent asthma and is not detectably altered by omalizumab. Before omalizumab, FceRI crosslinking with anti-IgE induced a robust production of all 3 inflammatory mediators. Within weeks of beginning omalizumab, anti-IgE-stimulated production of IL-4, IL8 and IL-13 measured over a 4-hour incubation period was significantly reduced. Six months after omalizumab withdrawal, anti-IgE-stimulated basophils generated as much or more of these cytokines than before treatment was initiated. The simplest interpretation of our data is that omalizumab causes a rapid and reversible downregulation of key FceRI-mediated basophil cytokine production. Since it was not feasible to explore more than 1 time point or concentration of stimulus, we recognize the formal possibility that a shift in either the antigen concentration or time dependence of cytokine production could generate the same results. As noted, our use of anti-IgE as stimulus is expected to engage essentially all available IgE-receptor complexes and to elicit the highest possible response. Thus, we anticipate an even greater reduction in cytokine production by basophils during omalizumab treatment when the stimulus is specific allergen.

Int Arch Allergy Immunol 2010;151:275-284 
IL-4 plays important pro-inflammatory functions in asthma including inducing the IgE isotype switch, increasing expression of vascular cell adhesion molecule-1, promoting eosinophil transmigration across endothelium, enhancing mucus secretion, and stimulating differentiation of Th2 lymphocytes leading to further cytokine synthesis and release [32-35]. IL-13 also causes Th2 cell differentiation and IgE production and induces many other features of allergic lung disease, including airway hyperresponsiveness, goblet cell metaplasia and mucus hypersecretion $[32,36]$. IL-8 is a potent chemoattractant for neutrophils and is also implicated in the enhanced airway responsiveness and airway remodeling observed in asthma [37]. Given the importance of these 3 mediators in allergic inflammation, it is possible that their reduced synthesis by basophils during omalizumab treatment contributes to the improvement of allergic inflammation and asthma symptoms that occurs in patients.

When Luminex multiplex technology became available, we extended the analysis of the same basophil supernatants using a Luminex panel that tests for a total of 32 cytokines, chemokines and growth factors. Luminex assays revealed the same pattern of response to anti-IgE and to omalizumab as already found by ELISA for IL-8 and IL-4. However, IL-13 was not detected. The apparent absence of IL-13 in the Luminex assay may be due to instability (the frozen supernatants were thawed for a second time for Luminex assays) or to a less sensitive antibody in the Luminex panel.

Two additional basophil products were explored. First, we found by Luminex that resting basophils release the chemokine RANTES and that activation using anti-IgE increases basophil RANTES production. Given RANTES' proposed role as a stimulator of basophil chemotaxis and degranulation $[26,33,38,39]$, it was of interest to determine if its production was reduced by omalizumab, possibly leading to reduced auto-stimulation as well as reduced stimulation of other target cells, including eosinophils, monocytes and T cells. A trend towards reduced RANTES production during omalizumab treatment was observed but statistical significance was not demonstrated.

In addition, Luminex data confirmed previous evidence [22] that basophils produce leptin. Initially thought to be an adipocyte-derived satiety factor that regulates body weight by inhibiting food intake and stimulating energy expenditure, this $16 \mathrm{kDa}$ adipokine was recently linked to the chronic asthma that is associated with obesity $[40,41]$. Statistical analysis of Luminex data failed to reveal any significant effect of either anti-IgE stimulation or omalizumab on production of this mediator. The role of basophil-derived leptin in human physiology remains to be discovered.

In summary, our results establish that depleting basophil FceRI expression reduces their FceRI-mediated synthesis of the asthma-promoting cytokines and chemokines, IL-4, IL-13 and IL-8. We speculate that asthma symptoms may improve during treatment with omalizumab in part because of the reduced synthesis of basophil cytokines and chemokines. Supporting this hypothesis, Falcone et al. [32, 33] have reported that human basophils are more important sources of IL- 4 and IL-13 than human mast cells and have proposed that basophils, despite their low numbers, can serve as both initiators and amplifiers of allergic inflammation in humans. Recent in vivo and in vitro work in mouse models has also strengthened the case for basophils as direct contributors to the initiation and progression of allergic inflammatory diseases and as targets for therapy [23, 24, 42-44].

The discovery here that anti-IgE-stimulated basophil Th2 cytokine synthesis is reduced following treatment that has no effect on anti-IgE-stimulated histamine release helps to differentiate the FceRI signaling properties of human basophils from those of FceRI-expressing rodent models such as rat RBL-2H3 cells and mouse bone marrow-derived mast cells. In cultured rodent cells, the synthesis and release of multiple cytokines, including IL4, persists under FceRI stimulus conditions that are too weak to support histamine release by degranulation [45, 46]. In contrast, we find that cross-linking very low numbers of FceRI on primary human basophils supports more histamine release than IL-4 and IL-13 production. Differences between rodent and human cells, between primary and cultured cells or between basophils and mast cells could all result in divergent FceRI signal regulation. That such differences exist emphasizes the importance of studying primary human cells in order to better understand and treat human asthma and other allergic diseases.

\section{Acknowledgements}

We are grateful for the generous cooperation of volunteers who participated in this study. We thank Genentech for providing omalizumab and Dr. C. Rick Lyons for providing access to his instrumentation for Luminex array analysis. This work was supported in part by NIH grants P50HL56384, RO1GM49814 and M01RR000997. 


\section{References}

$\checkmark 1$ Schulman ES: Development of a monoclonal anti-immunoglobulin E antibody (omalizumab) for the treatment of allergic respiratory disorders. Am J Respir Crit Care Med 2001;164:S6-S11.

\2 Busse W, Corren J, Lanier BQ, McAley M, Fowler-Taylor A, Della Cioppa G, Van As A, Gupta N: Omalizumab, anti-IgE recombinant humanized monoclonal antibody, for the treatment of severe allergic asthma. J Allergy Clin Immunol 2001;108:184-190.

$\checkmark 3$ Holgate S, Casale T, Wenzel S, Bousquet J, Deniz Y, Reisner C: The anti-inflammatory effects of omalizumab confirm the central role of IgE in allergic inflammation. J Allergy Clin Immunol 2005;115:459-465.

$\checkmark 4$ Fahy JV, Fleming HE, Wong HH, Liu JT, Su JQ, Reimann J, Fick RB, Boushey HA: The effect of an anti-IgE monoclonal antibody on the early- and late-phase responses to allergen inhalation in asthmatic subjects. Am J Respir Crit Care Med 1997;155:1828-1834.

$\checkmark 5$ Milgrom H, Fick RB, Su JQ, Reimann JD, Bush RK, Watrous ML, Metzger WJ: Treatment of allergic asthma with monoclonal anti-IgE antibody. New Engl J Med 1999;341: 1966-1973.

$\checkmark 6$ Spector S: Omalizumab: efficacy in allergic disease. Panminerva Med 2004;46:141-148.

-7 Finn A, Gross G, van Bavel J, Lee T, Windom H, Everhard F, Fowler-Taylor A, Liu G, Gupta N: Omalizumab improves asthma-related quality of life in patients with severe allergic asthma. J Allergy Clin Immunol 2003;111: 278-284.

8 Soler M, Matz J, Townley R, Buhl R, O’Brien J, Fox H, Thirwell J, Gupta N, Della Cioppa G: The anti-IgE antibody omalizumab reduces exacerbations and steroid requirement in allergic asthmatics. Eur Respir J 2001;18: 254-261.

-9 Fahy JV: Anti-IgE: lessons learned from effects on airway inflammation and asthma exacerbation. J Allergy Clin Immunol 2006; 117:1230-1232.

10 Djukanovic R, Wilson SJ, Kraft M, Jarjour NN, Steel M, Chung KF, Bao W, Fowler-Taylor A, Matthews J, Busse WW, Holgate ST, Fahy JV: Effects of treatment with anti-immunoglobulin E antibody omalizumab on airway inflammation in allergic asthma. Am J Respir Crit Care Med 2004;170:583-593.

- 11 MacGlashan DW, Bochner BS, Adelman DC, Jardieu PM, Togias A, McKenzie-White J, Sterbinsky SA, Hamilton RG, Lichtenstein LM: Down-regulation of Fc $\in$ RI expression on human basophils during in vivo treatment of atopic patients with anti-IgE antibody. J Immunol 1997;158:1438-1445.
12 Saini SS, MacGlashan DW, Sterbinsky SA, Togias A, Adelman DC, Lichtenstein LM Bochner BS: Down-regulation of human basophil IgE and FceRI $\alpha$ surface densities and mediator release by anti-IgE-infusions is reversible in vitro and in vivo. J Immunol 1999; 162:5624-5630.

13 Beck LA, Marcotte GV, McGlashan D, Togias A, Saini S: Omalizumab-induced reduc tions in mast cell FceRI expression and function. J Allergy Clin Immunol 2004;114 527-530.

14 MacGlashan DW, Xia HZ, Schwartz LB, Gong JP: IgE-regulated loss, not IgE-regulated synthesis, controls expression of FceRI in human basophils. J Leukoc Biol 2001;70: 207-218.

15 Brunner T, Heusser CH, Dahinden CA: Human peripheral blood basophils primed by interleukin 3 (IL-3) produce IL-4 in response to immunoglobulin E receptor stimulation. J Exp Med 1993;177:605-611.

16 Ochensberger B, Daepp GC, Rihs S, Dahinden CA: Human blood basophils produce interleukin-13 in response to IgE-receptor-dependent and -independent activation. Blood 1996;88:3028-3037.

17 Gibbs BF, Haas H, Falcone FH, Albrecht C, Vollrath IB, Noll T, Wolff HH, Amon U: Purified human peripheral blood basophils release interleukin-13 and preformed interleukin-4 following immunological activation. Eur J Immunol 1996;26:2493-2498.

18 Redrup AC, Howard BP, MacGlashan DW Kagey-Sobotka A, Lichtenstein LM, Schroeder JT: Differential regulation of IL-4 and IL-13 secretion by human basophils: their relationship to histamine release in mixed leukocyte cultures. J Immunol 1998;160:19571964.

-19 Kepley CL, Youssef L, Andrews RP, Wilson BS, Oliver JM: Syk-deficient non-releaser basophils show multiple functional defects in FceRI signaling: partial recovery of Syk expression and signaling by incubation with IL-3. J Immunol 2000;165:5913-5920.

20 Schroeder JT, MacGlashan DW, Lichtenstein LM: Human basophils: mediator release and cytokine production. Adv Immunol 2001;77: 93-122.

-21 Youssef LA, Schuyler M, Gilmartin L, Pickett G, Bard JDJ, Tarleton CA, Archibeque T, Qualls C, Wilson BS, Oliver JM: Histamine release from the basophils of control and asthmatic subjects and a comparison of gene expression between 'releaser' and 'nonreleaser' basophils. J Immunol 2007;178:45844594.

>22 Gilmartin L, Tarleton CA, Schuyler M, Wilson BS, Oliver JM: A comparison of inflammatory mediators released by basophils of asthmatic and control subjects in response to high affinity IgE receptor aggregation. Int Arch Allergy Immunol 2008;145:182-192.
23 Mukai K, Matsuoka K, Taya C, Suzuki H, Yokozeki H, Nishioka K, Hirokawa K, Etori M, Yamashita M, Kubota T, Minegishi Y, Yonekawa $\mathrm{H}$, Karasuyama $\mathrm{H}$ : Basophils play a critical role in the development of IgE-mediated chronic allergic inflammation independently of $\mathrm{T}$ cells and mast cells. Immunity 2005;23:191-202.

24 Obata K, Mukai K, Tsujimura Y, Ishiwata K, Kawano Y, Minegishi Y, Watanabe N, Karasuyama $\mathrm{H}$ : Basophils are essential initators of a novel type of allergic inflammation. Blood 2007;110:913-920.

-25 Dupont NC, Wang K, Wadhwa RD, Culhane JF, Nelson EL: Validation and comparison of luminex multiplex cytokine analysis kits with ELISA: determination of a panel of nine cytokines in clinical sample culture supernatants. J Reprod Immunol 2005;66:175191.

26 Marone G, Triggiani M, de Paulis A: Mast cells and basophils: friends as well as foes in bronchial asthma? Trends Immunol 2005; 26:25-31.

27 Bradding $\mathrm{P}$, Walls AF, Holgate ST: The role of the mast cell in the pathophysiology of asthma. J Allergy Clin Immunol 2006;117: 1277-1284.

28 Prussin C, Griffith DT, Boesel KM, Lin H, Foster B, Casale TB: Omalizumab treatment downregulates dendritic cell FceRI expression. J Allergy Clin Immunol 2003;112:11471154

29 Dy M, Schneider E: Histamine-cytokine connection in immunity and hematopoiesis. Cytokine Growth Factor Rev 2004;15:393410.

30 Nakajima H, Takatsu K: Role of cytokines in allergic airway inflammation. Int Arch Allergy Immunol 2007;142:265-273.

31 Lichtenstein LM, Bochner BS: The role of basophils in asthma. Ann N Y Acad Sci 1991; 629:48-61.

32 Falcone FH, Haas H, Gibbs BF: The human basophil: a new appreciation of its role in immune responses. Blood 2000;96:4028-4038.

33 Falcone FH, Zillikens D, Gibbs BF: The 21st century renaissance of the basophil? Current insights into their role in allergic responses and innate immunity. Exp Dermatol 2006; 15:855-864.

-34 Nouri-Aria KT, Irani AM, Jacobson MR, O'Brien F, Varga EM, Till SJ, Durham SR, Schwartz LB: Basophil recruitment and IL-4 production during human allergen-induced late asthma. J Allergy Clin Immunol 2001; 108:205-211.

-35 Steinke JW, Borish L: Th2 cytokines and asthma interleukin-4: its role in the pathogenesis of asthma, and targeting it for asthma treatment with interleukin-4 receptor antagonists. Respir Res 2001;2:66-70. 
-36 Wills-Karp M: Interleukin-13 in asthma pathogenesis. Immunol Rev 2004;202:175190.

\37 Govindaraju V, Michoud MC, Al-Chalabi M, Ferraro P, Powell WS, Martin JG: Interleukin-8: novel roles in human airway smooth muscle cell contraction and migration. Am J Physiol Cell Physiol 2006;291: C957-C965.

38 Conti P, Reale M, Barbacane RC, Frydas S, Felaco M, Grilli A, Placido FC, Cataldo I, Feliciani C, Di Gioaccino M, Anogianakis G, Dimitriadou D, Vacalis D, Trakatellis A: Massive infiltration of basophilic cells in inflamed tissue after injection of RANTES. Immunol Lett 1997;58:101-106.
39 Romagnani S: Cytokines and chemoattractants in allergic inflammation. Mol Immunol 2002;38:881-885.

40 Beuther DA, Weiss ST, Sutherland ER: Pulmonary perspective - obesity and asthma. Am J Respir Crit Care Med 2006;174:112119.

41 Sood A, Ford ES, Camargo CA: Association between leptin and asthma in adults. Thorax 2006;61:300-305.

42 Sokol CL, Barton GM, Farr AG, Medzhitov R: A mechanism for the initiation of allergen-induced T helper type 2 responses. Nat Immunol 2008;9:223-225.

43 Obata K, Mukai K, Tsujimura Y, Ishiwata K, Kawano Y, Minegishi Y, Watanabe N, Karasuyama $\mathrm{H}$ : Basophils are essential initiators of a novel type of chronic allergic inflammation. Blood 2007;110:913-920.
44 Oh K, Shen T, Le Gros G, Min B: Induction of Th2 type immunity in a mouse system reveals a novel immunoregulatory role of basophils. Blood 2007;109:2921-2927.

45 Gonzalez-Espinosa C, Odom S, Olivera A, Hobson JP, Cid Martinez ME, Oliveira-dosSantos A, Barra L, Spiegel S, Penninger JF, Rivera J: Preferential signaling and induction of allergy-promoting lymphokines upon weak stimulation of the high affinity IgE receptor on mast cells. J Exp Med 2003;197: 1453-1465.

46 Rivera J: Adaptors discriminate mast-cell cytokine production from eicosanoid production and degranulation. Trends Immunol 2006;27:251-253. 